\title{
A randomized, double blind, placebo controlled, multicenter clinical trial to assess the efficacy and safety of Emblica officinalis extract in patients with dyslipidemia
}

\author{
Haridas Upadya', S. Prabhu², Aravinda Prasad ${ }^{3}$, Deepa Subramanian ${ }^{4}$, Swati Gupta ${ }^{5^{*}}$ and Ajay Goel $6^{6^{*}}$
}

\begin{abstract}
Background: Dyslipidemia is one of the most frequently implicated risk factors for development of atherosclerosis. This study evaluated the efficacy of amla (Emblica officinalis) extract (composed of polyphenols, triterpenoids, oils etc. as found in the fresh wild amla fruit) in patients with dyslipidemia.

Methods: A total of 98 dyslipidemic patients were enrolled and divided into amla and placebo groups. Amla extract $(500 \mathrm{mg})$ or a matching placebo capsule was administered twice daily for 12 weeks to the respective group of patients. The patients were followed up for 12 weeks and efficacy of study medication was assessed by analyzing lipid profile. Other parameters evaluated were apolipoprotein B (Apo B), apolipoprotein A1 (Apo A1), Coenzyme Q10 (CoQ10), high-sensitive C-reactive protein (hsCRP), fasting blood sugar (FBS), homocysteine and thyroid stimulating hormone (TSH).

Results: In 12 weeks, the major lipids such as total cholesterol (TC) $(p=0.0003)$, triglyceride (TG) $(p=0.0003)$, low density lipoprotein cholesterol $(L D L-C)(p=0.0064)$ and very low density lipoprotein cholesterol (VLDL-C) $(p=0$. 0001) were significantly lower in amla group as compared to placebo group. Additionally, a 39\% reduction in atherogenic index of the plasma (AIP) ( $p=0.0177)$ was also noted in amla group. The ratio of Apo B to Apo A1 was reduced more $(p=0.0866)$ in the amla group as compared to the placebo. There was no significant change in CoQ10 level of amla $(p=0.2942)$ or placebo groups $(p=0.6744)$. Although there was a general trend of FBS reduction, the numbers of participants who may be classified as pre-diabetes and diabetes groups (FBS > $100 \mathrm{mg}$ / dl) in the amla group were only 8 . These results show that the amla extract used in the study is potentially a hypoglycaemic as well. However, this needs reconfirmation in a larger study.

(Continued on next page)
\end{abstract}

\footnotetext{
* Correspondence: swatigupta@aims.amrita.edu; Ajay.Goel@BSWHealth.org ${ }^{5}$ Amrita School of Pharmacy, Amrita Institute of Medical Sciences and Research Centre, Amrita Vishwa Vidyapeetham, Kochi 682041, India ${ }^{6}$ Center for Gastrointestinal Research, Center for Translational Genomics and Oncology, Baylor Scott \& White Research Institute and Sammons Cancer Center, Baylor University Medical Center, Dallas, Texas, 3410 Worth Street, Suite 610, Dallas, TX 75246, USA

Full list of author information is available at the end of the article
}

(c) The Author(s). 2019 Open Access This article is distributed under the terms of the Creative Commons Attribution 4.0 International License (http://creativecommons.org/licenses/by/4.0/), which permits unrestricted use, distribution, and reproduction in any medium, provided you give appropriate credit to the original author(s) and the source, provide a link to the Creative Commons license, and indicate if changes were made. The Creative Commons Public Domain Dedication waiver (http://creativecommons.org/publicdomain/zero/1.0/) applies to the data made available in this article, unless otherwise stated. 
(Continued from previous page)

Conclusions: The Amla extract has shown significant potential in reducing TC and TG levels as well as lipid ratios, AIP and apoB/apo A-I in dyslipidemic persons and thus has scope to treat general as well as diabetic dyslipidemia. A single agent to reduce cholesterol as well as TG is rare. Cholesterol reduction is achieved without concomitant reduction of Co Q10, in contrast to what is observed with statins.

Trial registration: Registered with Clinical Trials Registry- India at www.ctri.nic.in (Registration number: CTRI/2015/ 04/005682) on 8 April 2015 (retrospectively registered).

Keywords: Emblica officinalis, Cholesterol, AIP, TG, CoQ10, Dyslipidemia

\section{Background}

Dyslipidemia is one of the major risk factors for development of atherosclerosis and other heart disorders [1]. This indicates a high level of lipids in the blood, of which includes triglycerides (TGs) and total cholesterol (TC). All over the world including Indian population, both genetic disorders and diets high in saturated fats and cholesterol, contribute to elevated lipid levels [2].A lot of efforts are being made worldwide to diagnose cardiovascular disease. The conventional lipid parameters include triglycerides (TGs), total cholesterol (TC), high density lipoproteins (HDL), low density lipoproteins (LDL) and very low density lipoproteins (VLDL). It is thus apparent that for effective management of dyslipidemia, several of the individual parameters need to be controlled simultaneously. This is amply demonstrated by the observation that people whose cholesterol has been brought to normal levels are not free from CVD risk. Several lipoprotein ratios have also been defined to optimize the predictive capacity of the lipid profile. Atherogenic index of plasma (AIP) is one such measure and could prove to be a better alternative to the simple lipid profile [3]. AIP is the logarithmically transformed ratio of molar concentrations of TGs to high density lipoproteins (HDL) ((log (TG/HDL $[\mathrm{mmol}]))$. AIP is increased in people at higher risk for coronary heart disease and has recently been identified as a marker of plasma atherogenicity. This simple ratio reflects the balance between atherogenic versus antiatherogenic lipids and is inversely correlated with LDL-C particle size. AIP is also associated with prediction of type 2 diabetes mellitus (T2DM). A recent meta-analysis of 15 studies suggest that conventional plasma lipid parameters have ability to predict the risk of T2DM, but AIP is the most important among all and may be more closely associated with the risk of T2DM. Almost all the studies reported in the meta-analysis reported positive associations between AIP and T2DM [4].

The apolipoproteins play very important role in lipoprotein metabolism [5]. The largest component of the HDL is apolipoprotein A1 (Apo A1). It's major role is acting as a mediator in transfer of cholesterol from cells to HDL particles. It also works as co-factor for lecithin cholesterol acyl transferase enzyme. Both of these two processes are very important for the reverse transport of cholesterol to the liver [6]. Apolipoprotein B (Apo B) is another important apolipoprotein which is present in chylomicrons, VLDL, IDL and LDL [7]. It is considered as the major functional protein which transports cholesterol to peripheral cells [8]. There is strong association between the risk of CVD and increased Apo B/Apo A1 ratios [9]. There are several prospective studies such as the AMORIS [10], INTERHEART [11], EPIC-Norfolk [12], ULSAM [13], and the MONICA/KORA [14] which confirms the importance of Apo B/Apo A1 ratios in predicting CVD. In one study with non-diabetic subjects, Apo B/Apo A-I ratio has been shown to be an independent predictor of insulin resistance [15]. The utility of this ratio is further supported by a meta-analysis as a future risk marker of CVD [16]. Conventional lipid indices alone may result in erroneous conclusions in the assessment of CVD risk [17]. A proportion of the subjects with accepted range of lipid parameters [18] and some patients who achieve significant decrease in LDL cholesterol levels with lipid lowering treatment [19] still develop atherosclerotic disease. Lipoprotein cholesterol concentration may not always correspond to lipoprotein concentration [20]. This discrepancy can be corrected by the apoB/apoA-1 ratio and discriminate between patients with CVD and those without even when they have normal lipid levels [21].

Various medicinal plants used in the traditional systems of medicine have shown potential in the management of dyslipidemia and CVD without major adverse events. Emblica officinalis (Amla or Indian gooseberry) is one such medicinal plant which has been shown to be effective in the management of dyslipidemia in experimental animals and in pilot clinical studies without major side effects [22, 23]. In vitro and animal studies have shown that the flavonoids from Emblica officinalis effectively reduce lipid levels in blood serum and tissues [24]. In a study in rabbits, amla extract was found effective in the management of dyslipidemia by reducing LDL and increasing HDL levels. The authors also reported that intima media thickening got reversed on administration of amla extract [25]. Few more reports are 
published on hypolipidemic effects of amla on cholesterol induced atherosclerosis in rabbits [26, 27]. In a pilot clinical study by Antony et al., Emblica officinalis extract at a dose of $500 \mathrm{mg}$ and $1000 \mathrm{mg}$ per day, showed a significant reduction in TC and TG and a significant increase in HDL. The inflammatory marker C-reactive protein (CRP) was also significantly reduced [28]. In this study the extract was aqueous extract of fresh amla fruits without seeds and standardized to 35\% galloelagi tannins. In another study by same group, $50 \%$ methanol extract of amla at $500 \mathrm{mg}$ twice daily reduced the TC, TG and LDL significantly and increased the HDL as compared to control group [29]. Another clinical study comparing the efficacy and safety of amla capsule $(500 \mathrm{mg} /$ day $)$ with simvastatin $(20 \mathrm{mg} /$ day $)$ has shown that amla produced significant reduction of TC, LDL, TG and VLDL, and a significant increase in HDL [30].

In all the above reported trials with amla extract, the main focus of researchers was on measurement of lipid profile only. Moreover, the amla extract used in above studies was made without using the amla seeds. The amla extract used in the present study is full spectrum amla fruit extract including the extract from amla seeds and amla fruit pulp. Furthermore, apart from conventional lipid parameters, we have also measured the AIP, apoB/apoA-1, CoQ10 level, TSH etc. which may provide a more conclusive prediction on heart health than lipid profile alone.

The primary objective of the present study was to assess the effect of amla extract on TG levels. Additionally, we also studied the AIP and apoB/apoA-1 ratios as reliable risk factors for CVD in patients suffering from dyslipidemia. Another objective of this study was to assess the safety of amla extract with emphasis on the side effects observed in conventional lipid lowering therapies.

This report pertains to the results of a randomized, multicentre study using an extract of amla (Indian gooseberry, Emblica officinalis) fruits to effectively reduce high TC and TG levels in persons. The extract also reduces apoB/apoA-I ratios potentially indicating its utility in treating diabetic dyslipidemia, in particular. Amla belongs to a group of plants classified as Rasayana plants under the Ayurvedic system of traditional medicine. Rasayana plants are known for their all-round health benefits and outstanding safety profiles.

\section{Methods}

\section{Study medication and placebo}

A $500 \mathrm{mg}$ capsule of amla extract (Arjuna Natural Ltd., Aluva, Kerala, India) was used for the intervention group. Amla extract was prepared by extracting fresh whole fruits of amla with ethyl acetate and standardized to contain not less than $35 \%$ polyphenols, $8 \%$ triterpenoids and 10\% oil. The extract also contains Omega 3 fatty acids. This is the first report on amla extract containing omega 3 fatty acids. The details on characterization of the amla extract used in the study are provided in the Additional file 1. Each $500 \mathrm{mg}$ of amla extract capsule contains about $175 \mathrm{mg}$ polyphenols, $40 \mathrm{mg}$ triterpenoids and $50 \mathrm{mg}$ oil. Similarly, $500 \mathrm{mg}$ placebo capsules (roasted rice powder) were used for control group. Vegetarian capsule shells of size ' 0 ' were filled with $500 \mathrm{mg}$ amla extract powder (intervention group) or roasted rice powder (placebo). Semi-automatic capsule filling machine was used to fill the required number of capsules.

\section{Impact of roasted rice (as placebo) in patients with dyslipidemia}

In the present study, roasted rice powder used as a placebo was given at a dosage of $500 \mathrm{mg}$ capsule twice daily for 12 weeks. Rice is known as the grain of life and is synonymous with food for every Indian. It is the staple food for two thirds of the Indian population [31]. The Indians derive $80 \%$ of their energy needs from rice, which contains about $80-90 \%$ carbohydrates, 7-8\% protein, $2-3 \%$ fat, and $1-2 \%$ fiber [32]. The major component of rice responsible for its medicinal value is the rice bran $[33,34]$. It is reported that, higher daily intakes of rice bran for longer duration is needed to induce favorable changes in serum lipid parameters [34]. The roasted rice powder used in the present study was prepared by taking white rice devoid of any husk, bran or germ. The dose was only $500 \mathrm{mg}$ twice daily which is very less compared to serving of rice as a regular meal. Thus, there was very negligible chance of any impact of roasted rice powder on lipid profile of patients with dyslipidemia.

\section{Chemicals}

Kits for TC, TG, LDL-C, HDL-C, VLDL-C, Apo A1, Apo B, TSH, plasma glucose, SGOT (serum glutamic oxaloacetic transaminase), SGPT (serum glutamic pyruvic transaminase), bilirubin, creatinine and blood urea nitrogen (BUN) were purchased from Siemens Limited, Mumbai, India. Human Coenzyme Q10 (CoQ10) kit was purchased from Elabscience, USA. All other chemicals were of analytical grade and purchased locally.

\section{Study design}

The study was a multicenter (a total of four study centers across South India; Additional file 2), randomized, double blind, parallel, placebo controlled, clinical trial to evaluate the efficacy and safety of amla extract $500 \mathrm{mg}$, compared to a placebo in patients with dyslipidemia (study protocol included as Additional file 3). The study followed CONSORT guidelines and criteria as illustrated in Fig. 1 and the Additional file 4. This was a parallel treatment study of 12 weeks duration. There were a total 


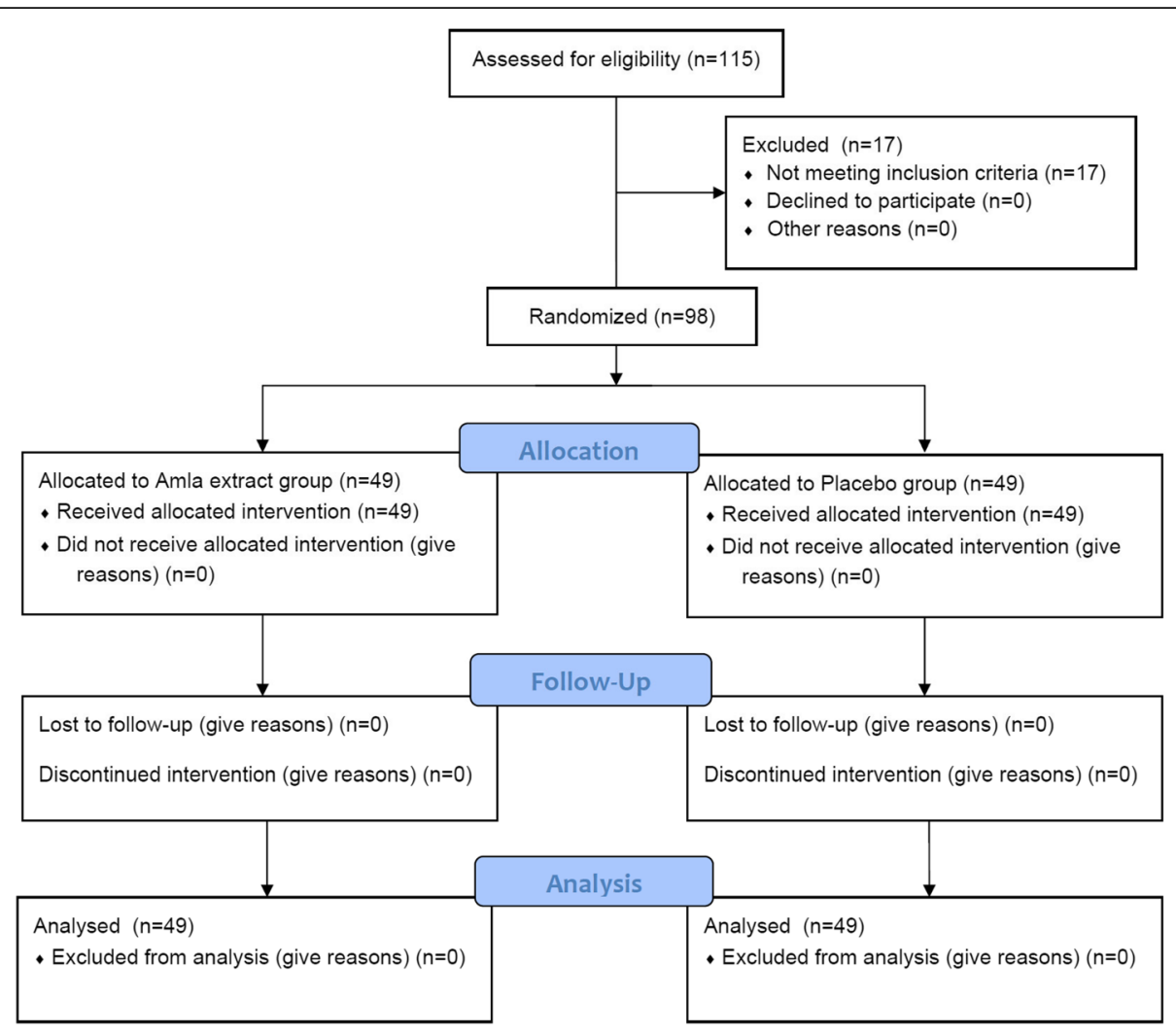

Fig. 1 The CONSORT Diagram

of 5 visits (Fig. 2): Visit 1 -Screening (Day - 7), Visit 2, Randomization (Day 0), Visit 3, Follow up (Day $28 \pm 5$ days), Visit 4, Follow up (Day $56 \pm 5$ days) and Visit 5 , End of study visit (Day $84 \pm 5$ days). Laboratory investigation of all efficacy parameters were conducted at screening, on all follow up visits and end of study visit while laboratory assessments for safety parameters were performed on Visit 1 (screening) and Visit 5 (end of the study). The study protocol was approved by respective institutional ethics committees, i.e. Mysore Clinical Research Ethics Committee on 22/2/2015 (study site: Aadhitya Adhikari Hospital, Contour Road, Gokulam, Mysore-570,002), Life Care Hospital Institutional Ethics Commitee on 15/3/2015 (study site: LifeCare Hospital, 99, OM Complex, 20th Main, Gangothri Circle, BTM 1st Stage, Bangalore-560,029), Sri Venkateshwara Hospital Ethics Committee on 15/3/2015 (Study site: Sri Venkateshwara Hospital, No.86, Hosur Main Road, Madiwala, Bangalore- 560,068) and Prashanth Hospital Ethics Committee on 17/3/2015 (study site: Prashanth Hospital, Bommanahalli Circle, Hosur Main Road, Bangalore-560,068) and and registered with Clinical Trials Registry- India at www.ctri.nic.in (Registration number: CTRI/2015/04/ 005682) on 8 April 2015 (retrospectively registered).

To maintain blindness of study treatments, placebo capsules resembling in every manner to amla extract capsule were used. Sealed envelopes/scratch cards were provided to the investigators by the sponsor (one each for each randomization number) indicating the randomization number and the test product contained therein. The sealed envelopes/scratch cards were kept by the investigator in a safe but accessible place should the need for breaking the blinding medication code arises in an emergency.

\section{Sample size}

Sample size was determined for t- test. For getting a power of $90 \%$, 39 patients would be needed in each group. Assuming the dropout, missing data etc., of $20 \%$, a total of 98 patients were enrolled comprising of 49 in each group.

\section{Study population}

A total of 98 patients, male and female, at multiple centers were simultaneously enrolled in this clinical trial. The enrolled patients were assigned to either of the two study groups according to the centralized computer generated randomization in a 1:1 ratio using Graph Pad Prism software. The study was conducted during March 2015 to November 2015. 


\section{Visit 1 (Day -7)}

Expression of interest/Assessed for eligibility $(n=115)$

Not meeting inclusion criteria $(n=17)$

Clinical and Lab investigations (Efficacy and safety); ECG

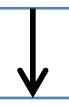

\section{Visit 2 (Day 0)}

Re-check for eligibility criteria

Clinical and Lab investigations (No blood collection)

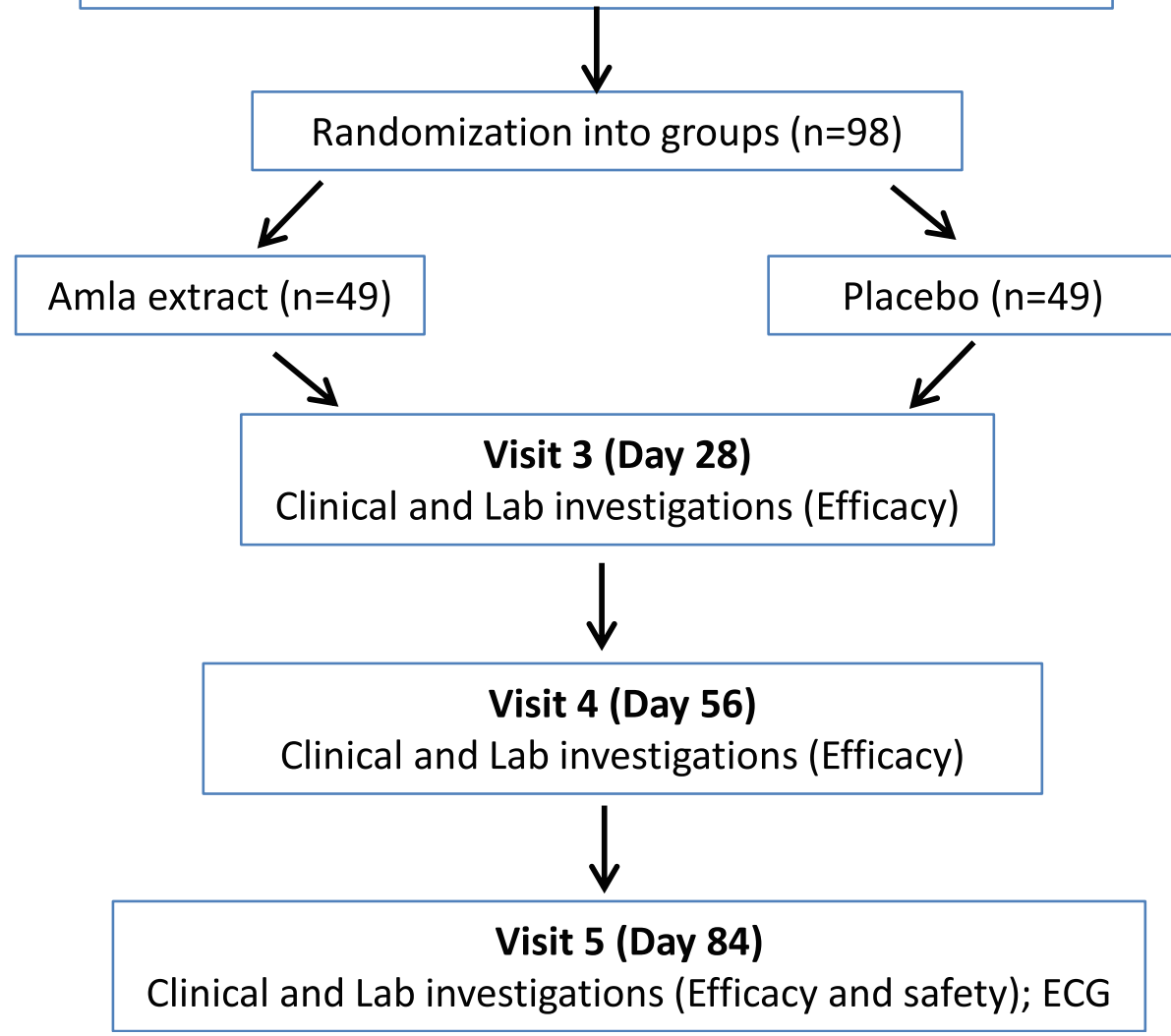

Fig. 2 Systemic illustration of study design

\section{Inclusion and exclusion criteria}

Any study related activity was undertaken only after subjects voluntarily signed the consent form. Patients (male/female) between 30 and 65 years of age having TG $>200 \mathrm{mg} / \mathrm{dL}, \mathrm{LDL}-\mathrm{C}>130 \mathrm{mg} / \mathrm{dL}, \mathrm{TC}>200 \mathrm{mg} / \mathrm{dL}$ and $\mathrm{HDL}-\mathrm{C}<40 \mathrm{mg} / \mathrm{dL}$ for men and $<50 \mathrm{mg} / \mathrm{dL}$ for women were included in the study. Patients were not taking any medication (including herbal product) for management of dyslipidemia since the last 4 weeks.

Patients with more than 2 of the following risk factors: Cigarette smoking, Hypertension (BP > 140/90 $\mathrm{mmHg}$ or on antihypertensive medication), Family history of premature CHD (CHD in male first degree relative < 55 years; CHD in female first degree relative $<65$ years), Age (men > 45 years; women > 55 years) were excluded from the study. Patients with uncontrolled cardiovascular disease or advanced atherosclerosis (e.g. history of stroke, myocardial infarction, life-threatening arrhythmia, or coronary revascularization within the preceding 6 months; unstable angina; congestive heart failure; known or suspected clinically significant valvular heart disease or uncontrolled hypertension ( $>160 / 100 \mathrm{~mm}$ of $\mathrm{Hg}$ or use of antihypertensive medications, dose of which is not stable in the last 1 month) were also excluded. Patients with TG levels > $500 \mathrm{mg} / \mathrm{dL}$ or FPG more than $150 \mathrm{mg} / \mathrm{dL}$, using insulin, 
glitazones, or other hypoglycemics, at a dose of which was not stable in last 1 month were also excluded.

Pregnancy, lactation and female patients not using acceptable contraceptive measures (double barrier methods, oral or injectable hormonal contraceptives or surgical sterilization), patients with hepatic impairment (SGOT or SGPT levels > 3 Upper Limit of Normal $(\mathrm{ULN})$ ) or renal impairment (serum creatinine $\geq 2.0 \mathrm{mg}$ / $\mathrm{dl})$, patients with any other severe systemic illness, those that in the opinion of the investigator would be noncompliant with the visit schedule or study procedures and patients with known history of hypersensitivity to Amla or any product containing Amla extract were also excluded. Patients with continuing history of alcohol and/or drug abuse, patients with any other serious concurrent illness or malignancy, or participating in another clinical trial in the past 3 months were also excluded.

\section{Study procedure}

The study was a double blind investigation, randomizing eligible patients using a centralized computer generated randomization plan to receive either $500 \mathrm{mg}$ amla extract capsule or the corresponding placebo twice daily (after breakfast in the morning and after dinner in the evening) for 12 weeks. All the patients enrolled in the study were also asked to initiate lifestyle changes (healthy diet with exercise at least 4 days a week) along with the study medication.

All patients were followed up on an outpatient basis for a period of 84 days \pm 5 days ( 12 weeks) with scheduled visits on day 28, day 56 and day 84 post-randomization. Efficacy assessments were carried out by laboratory investigations on each of the scheduled visits (except the randomization visit). Clinical adverse events monitoring was done on each visit and complete laboratory check-ups (both haematological and biochemical) and ECG were repeated at the end of the study (12 weeks), so as to assess the safety of the study medication. Laboratory values obtained during the screening/randomization visit were considered as baseline values for efficacy and safety analysis.

\section{Assessment of efficacy}

The venous blood samples were collected from the participants during each visit after overnight (12 h) fasting to measure the efficacy and safety parameters. Efficacy of the study medication was assessed by the primary serum lipid parameters: TG, TC, LDL-C, VLDL-C and HDL-C. The AIP was calculated by taking logarithm to the base 10 (Common Logarithm) of the ratio of the molar concentration of TG to HDL-C [35]. Other important parameters measured were Apo A1 \& Apo B and Coenzyme Q10 (CoQ10). The ratio of Apo B to Apo A1 was calculated. Other related parameters like fasting plasma glucose (FPG), homocysteine levels, and
TSH were also analyzed. The tests were conducted as per procedure available with the respective kits. The treatment compliance was calculated on the basis of number of capsules unit left in the bottle at each follow up visits.

\section{Statistical analysis}

Statistical analysis was conducted using SPSS version 24.0 for Windows. Continuous variables were expressed as means and standard deviations and discrete variables were expressed as proportions. Chi square test was used for comparing the proportions. Normally distributed data were analysed using independent $t$-test to determine the statistical significance between groups and paired t-test was used to analyse within the group. For non-normally distributed data were analysed using Mann-Whitney to find the significance between the groups and and within the groups for such data Wilcoxon signed rank test was used. Additionally ANOVA with repeated measure is done after doing Mauchly's test for sphericity. If Mauchly's test statistic is non-significant $(p>0.05)$ it is reasonable to conclude that the variances of differences are not significantly different (i.e. they are roughly equal) and sphericity is assumed, otherwise sphericity is not met and Greenhouse-Giesser values are used to calculate the F-statistics and corresponding eta-square is calculated. A value of eta-square $0.01-0.06$ is considered as small effect, 0.06-0.14, medium effect and above 0.14 large effect. The mean scores for clinical parameters were statistically significantly different if $p$ value for $\mathrm{F}$ statistics were less than 0.05 . The mean difference of each parameter between different time point were calculated and if $p<0.05$ the change is significant between different time points. Single tailed, Wilcoxon signed rank test, Wilcoxon Rank Sum Test (Mann-Whitney) and ANCOVA were used for statistical analysis of clinical parameters to compare the groups and change within the group between the base line data and final data. A p value of less than 0.05 was considered as significant. The power of the study is $80 \%$ as the mean reduction of the primary end point (TG) and SD of TG did not vary much from the initially assumed values taken at the time of study design.

\section{Results}

\section{Demographic details and baseline data}

A total of 98 patients (45 males and 53 females) were enrolled and all the patients completed the study at multiple centers in India. The patient demographic characteristics are shown in Table 1, and indicate that the study population was homogenous, with no statistically significant differences between the groups with respect to demographic variables. There was no dropout 
Table 1 Subject's baseline data at the start of the study

\begin{tabular}{|c|c|c|c|}
\hline Parameters & Patients treated with Amla Extract (Mean \pm S.D) & Patients treated with Placebo (Mean \pm S.D) & $p$-value \\
\hline Age (years) & $40.7 \pm 10.13$ & $42.2 \pm 9.20$ & 0.44 \\
\hline Height (cm) & $162.7 \pm 9.20$ & $163.1 \pm 9.54$ & 0.82 \\
\hline Weight (kg) & $70.4 \pm 10.57$ & $69.8 \pm 9.04$ & 0.75 \\
\hline Number of participants & 49 & 49 & \\
\hline Number of male subjects & 22 & 23 & 0.84 \\
\hline Number of female subjects & 27 & 26 & \\
\hline Body Mass Index (BMl; $\mathrm{Kg} / \mathrm{m}^{2}$ ) & $26.9 \pm 3.77$ & $26.1 \pm 3.39$ & 0.27 \\
\hline Systolic Blood Pressure (mmHg) & $118.1 \pm 5.77$ & $119.7 \pm 5.19$ & 0.15 \\
\hline Diastolic Blood Pressure $(\mathrm{mmHg})$ & $77.9 \pm 6.87$ & $77.4 \pm 7.06$ & 0.72 \\
\hline Heart Rate (Beats per minute) & $77.5 \pm 6.11$ & $77.1 \pm 6.52$ & 0.75 \\
\hline Axillary Temperature (degrees Celcius) & $36.96 \pm 0.243$ & $36.94 \pm 0.308$ & 0.72 \\
\hline Total cholesterol (mg/dL) & $231.7 \pm 27.03$ & $225.7 \pm 29.03$ & 0.27 \\
\hline Triglycerides (mg/dL) & $261.1 \pm 74.13$ & $247.6 \pm 57.70$ & 0.84 \\
\hline High Density Lipoproteins (mg/dL) & $43.7 \pm 7.45$ & $43.4 \pm 7.34$ & 0.09 \\
\hline Low Density Lipoproteins (mg/dL) & $140.0 \pm 19.66$ & $132.2 \pm 20.82$ & 0.06 \\
\hline Very Low Density Lipoproteins (mg/dL) & $51.7 \pm 15.9$ & $49.6 \pm 11.68$ & 0.70 \\
\hline Atherogenic index of Plasma & $0.43 \pm 0.14$ & $0.41 \pm 0.12$ & 0.82 \\
\hline Fasting Plasma Glucose (mg/dL) & $90.6 \pm 26.83$ & $91.9 \pm 22.12$ & 0.44 \\
\hline Ratio of Apo B to Apo A1 & $1.0 \pm 0.34$ & $0.87 \pm 0.22$ & 0.35 \\
\hline CoQ10 (ng/ml) & $471.5 \pm 183.5$ & $487.0 \pm 167.5$ & 0.27 \\
\hline HMGCoA (ng/ml) & $62.4 \pm 11.06$ & $53.4 \pm 7.07$ & 0.48 \\
\hline Glycolated Hb & $6.25+1.05$ & $6.22+1.11$ & 0.47 \\
\hline Homocystiene ( $\mu \mathrm{mol} / \mathrm{L})$ & $23.58 \pm 14.57$ & $21.4 \pm 11.10$ & 0.36 \\
\hline TSH $(\mu \mathrm{lU} / \mathrm{ml})$ & $2.43 \pm 1.50$ & $2.53 \pm 2.58$ & 0.33 \\
\hline CRP & $3.71+5.82$ & $4.58+5.96$ & 0.10 \\
\hline Blood Urea (mg/dl) & $9.7 \pm 3.42$ & $10.2 \pm 5.39$ & 0.93 \\
\hline $\mathrm{Hb}$ & $14.03 \pm 2.34$ & $13.89 \pm 2.04$ & 0.48 \\
\hline Serum Creatinine-(mg/dl) & $0.8 \pm 0.15$ & $0.9 \pm 0.60$ & 0.64 \\
\hline Serum Bilirubin-(mg/dl) & $0.6 \pm 0.32$ & $0.6 \pm 0.28$ & 0.28 \\
\hline SGOT (U/L) & $27.2 \pm 10.23$ & $27.4 \pm 9.35$ & 0.98 \\
\hline SGPT (U/L) & $38.6 \pm 20.86$ & $37.2 \pm 18.56$ & 0.88 \\
\hline
\end{tabular}

reported in the study. The vital parameters i.e. blood pressure, heart-rate, axillary temperature, respiratory rate, etc. were in normal range before start of the study. There was no significant difference in vital parameters at baseline and at the end of study (visit 5) in amla extract as well as the placebo group.

Triglyceride, HDL-C and Atherogenic index of plasma

There was a highly significant reduction in TG from $261.11 \pm 74.13 \mathrm{mg} / \mathrm{dl}$ (baseline) to $171.94 \pm 86.51 \mathrm{mg} / \mathrm{dl}$ (visit 5$)$ in the amla extract group $(p<0.0001$ within the group), whereas the TG reduction in the placebo group was from $247.62 \pm 57.70 \mathrm{mg} / \mathrm{dl}$ to $210.47 \pm 65.27 \mathrm{mg} / \mathrm{dl}$ (Fig. 3a). This reduction in TG was also highly significant $(p=0.0003)$ between the groups. AIP was reduced from $0.43 \pm 0.14$ to $0.26 \pm 0.20$ in amla extract group ( $p<0.0001$ within the group) whereas reduction was from $0.41 \pm 0.12$ to $0.35 \pm 0.15$ in the placebo group (Fig. 3b). The change in AIP was also highly significant between the two groups $(p=0.0177)$. The change in HDL from baseline to visit 5 was not significant between the groups. The complete data for all the visits is available as Additional file 5.

\section{Ratio of Apo B to Apo A1}

The data for the ratio of Apo B to Apo A1 is presented in Fig. 3c. The ratio of Apo B to Apo A1 significantly reduced from $1.00 \pm 0.34$ to $0.94 \pm 0.29$ in amla extract 
A

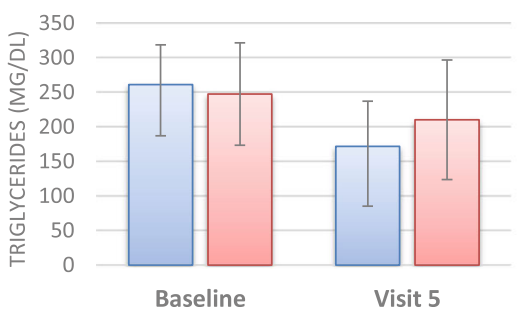

$\square$ Amla extract $\square$ Placebo

\section{C}

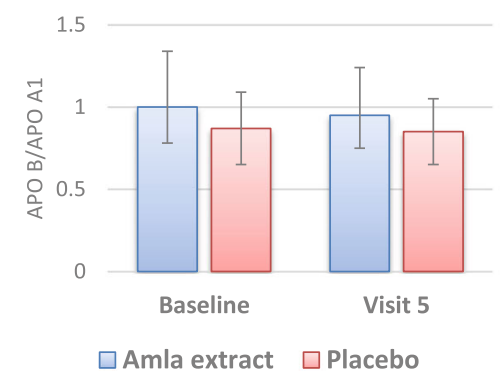

E

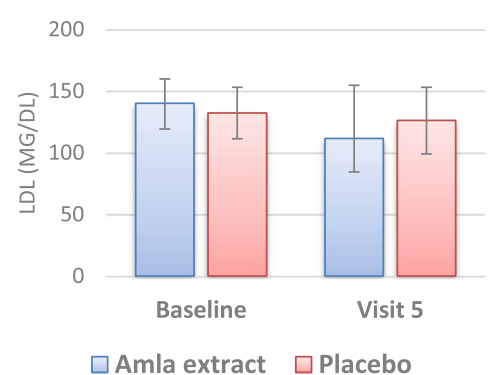

B

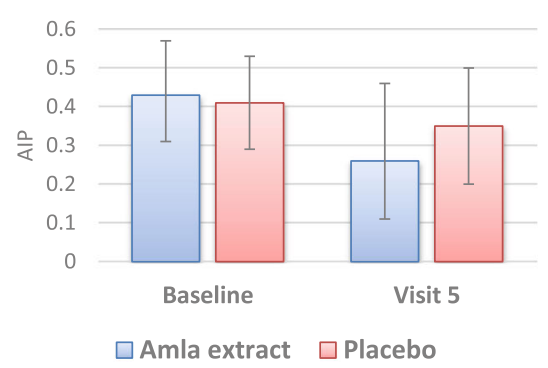

D

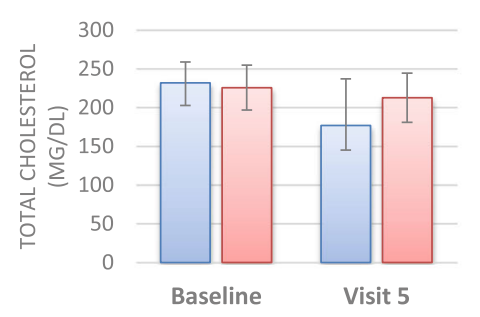

$\square$ Amla extract $\square$ Placebo

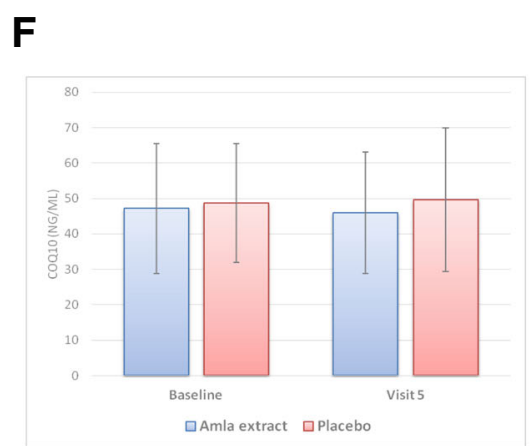

Fig. 3 (a) Triglyceride level in amla extract and placebo group ( $p=0.0003$ between the groups); (b) Atherogenic index of plasma in amla extract and placebo group ( $p=0.0177$ between the groups); (c) Ratio of Apo B to Apo A1 at baseline and visit 5 in amla extract and placebo group ( $p=0.0866$ between the groups); (d) TC level at baseline and visit 5 in amla extract and placebo group ( $p=0.0003$ between the groups); (e) LDL-C level at baseline and visit 5 in amla extract and placebo group ( $p=0.0064$ between the groups); (f) CoQ10 level at baseline and visit 5 in amla extract and placebo group ( $p=0.4581$ between the groups)

group ( $p=0.0419$ within the group) whereas in placebo group the ratio was decreased (non-significant) from $0.87 \pm 0.22$ to $0.85 \pm 0.20$ ( $p=0.6434$ within the group). There was no significant difference between the groups $(p=0.0866)$ in ratio of Apo B to Apo A1.

\section{TC, LDL-C and VLDL-C level}

In the amla extract group, the TC was significantly reduced from $231.67 \pm 27.03 \mathrm{mg} / \mathrm{dl}$ (baseline) to $177.00 \pm 60.04 \mathrm{mg} /$ $\mathrm{dl}$ (visit 5) after 12 weeks of treatment $(p<0.0001$ within the group). In the placebo group, TC was reduced from $225.74 \pm 29.03 \mathrm{mg} / \mathrm{dl}$ (baseline) to $212.55 \pm 31.78$ $\mathrm{mg} / \mathrm{dl}$ ( $p=0.0098$ within the group). The reduction in TC was highly significant $(p=0.0003)$ between amla extract and placebo group (Fig. 3d). LDL-C was significantly reduced from $139.96 \pm 19.66 \mathrm{mg} / \mathrm{dl}$ to $111.53 \pm 43.22 \mathrm{mg} / \mathrm{dl}$ in amla extract group $(p<0.0001$ within the group) whereas in placebo group the baseline LDL-C was $132.15 \pm 20.82 \mathrm{mg} / \mathrm{dl}$ and reduced to $126.06 \pm 27.02 \mathrm{mg} / \mathrm{dl}$ at the end of study $(p=0.1008$ within the group). This reduction in LDL-C was also highly significant $(p=0.0064)$ between the two groups (Fig. 3e). VLDL-C was also reduced in both the groups after 12 weeks treatment. In amla extract 
group the VLDL-C was significantly reduced from $50.56 \pm 15.9 \mathrm{mg} / \mathrm{dl}$ to $33.04 \pm 17.32 \mathrm{mg} / \mathrm{dl} \quad(p<0.0001$ within the group) whereas in placebo group, the change was from $50.72 \pm 11.68 \mathrm{mg} / \mathrm{dl}$ to $42.79 \pm 12.89$ $\mathrm{mg} / \mathrm{dl}$ ( $p=0.0003$ within the group). The reduction in VLDL-C was also highly significant $(p=0.0001)$ between the two groups.

\section{CoQ10 level}

As presented in Fig. 3f, there was a very slight change (not significant; $p=0.2942$ within the group) in CoQ10 level in the amla extract group from $47.15 \pm 18.27 \mathrm{ng} / \mathrm{ml}$ (baseline) to $45.98 \pm 17.15 \mathrm{ng} / \mathrm{ml}$ (visit 5), whereas change in the placebo group was from $48.69 \pm 16.75 \mathrm{ng} /$ $\mathrm{ml}$ to $49.60 \pm 20.32 \mathrm{ng} / \mathrm{ml}$ ( $p=0.6744$ within the group). The change in CoQ10 level was not statistically significant between the groups $(p=0.4581)$ or between baseline and at the end of the study.

\section{Other efficacy parameters}

The homocysteine level was reduced in the amla extract group from $23.58 \pm 14.57 \mu \mathrm{mol} / \mathrm{L}$ (baseline) to $19.17 \pm 8.93 \mu \mathrm{mol} / \mathrm{L}$ (visit 5), whereas the reduction in the placebo group was from $21.4 \pm 11.10 \mu \mathrm{mol} / \mathrm{L}$ to $17.18 \pm 5.8 \mu \mathrm{mol} / \mathrm{L}$. The change in homocysteine level was not statistically significant between the groups $(p>0.05)$. There was an increase in the TSH level of amla extract as well as placebo groups when baseline values were compared with visit 5 values and the change was more in placebo group. In this case also the increase in TSH level was not statistically significant between the groups. The change in FPG level was also not significant between amla extract and placebo groups. The $p$ values within the group and between groups are mentioned in Table 2 for all the parameters.

\section{Safety parameters}

In the safety assessments, vital signs like systolic and diastolic blood pressure, heart rate, axillary temperature, respiratory rate were normal on the screening visits and during the study visits. No statistically significant changes in vital signs were observed between the groups. Routine urine parameters, hematology and biochemistry (SGOT, SGPT, serum bilirubin, serum creatinine, blood urea etc.) were also normal at baseline and throughout the study. The complete safety data is available as Additional file 6.

There were no withdrawals or drop outs reported and all 98 subjects completed the study with a good compliance to the study supplements. There were four adverse events reported in the study. One patient reported mild fever, one had mild headache and two patients reported mild gastritis. The site investigator classified these as mild in nature and having possible relationship with the product and resolved with routine medications. The un-blinding of the study groups revealed that three of the adverse events reported, were in patients belonging to the placebo group; the other one was amla extract group. Overall treatment compliance was extremely high with the Mean Value (MV $=87.5 \%$ ) between both study arms $(87.7 \%$ for amla extract and $87.3 \%$ for placebo).

\section{Discussion}

The basic task of dealing with the epidemic of vascular diseases is primary prevention of dyslipidemia contributed by high blood cholesterol (TC) and triglycerides (TG) and associated lipoproteins. A single agent to treat the condition has not been available so far. Type 2 diabetes is associated with enhanced risk for CVD and ideally this condition also needs to be treated by the same agent. If such an agent is available, polypharmacy and associated adverse effects of consuming several drugs can be avoided. The results of the present study demonstrate the potential of a proprietary amla extract (TRI-LOW, Arjuna Natural Ltd., India) to adorn the role of such a single agent. Significant positive changes in individual lipid parameters have been achieved during a 12-week treatment regimen. However, the ability of the extract to treat hyperglycemia associated with T2DM needs to be reconfirmed since the only limited numbers of diabetics were included in the present study population.

Of the 49 participants of the amla group, 36 (73\%) showed significant reduction in TC. A similar number showed reduction in LDL-C with several of them (26, $53 \%)$ achieving normal levels $(<100 \mathrm{mg} / \mathrm{dl})$. Similary, 44 out of 49 participants achieved significant TG reduction. The extract had only marginal and insignificant effect on HDL-C levels. Results of VLDL-C levels were excellent with only 6 participants not responding to treatment. All except 8 participants achieved normal VLDL-C levels $(<30 \mathrm{mg} / \mathrm{dl})$. Lipoprotein remnants, of which the most accessible is VLDL-C are TG-rich, increase CVD risk when TG levels are above $200 \mathrm{mg} / \mathrm{dl}$ [36], a criterion relevent to the present study population. Thus, the amla extract could favorably modulate all the significant lipid parameters. Results are in Table 2.

It was recognized early that results of single lipid parameters have limited success in risk prediction, and in efforts to improve CVD risk prediction, several lipid ratios have been defined. We employed two of the most useful of these ratios, namely, AIP and apoB/apoA-I. Both more or less predict the atherogenic versus antiatherogenic potential of a particular set of lipid parameters. AIP, expressed as $\log (\mathrm{TG} / \mathrm{HDL}(\mathrm{mmol}))$, has been proposed as a marker of plasma atherogenicity because the ratio is increased in people at higher risk CVD. AIP is also inversely correlated with LDL particle size, a 
Table 2 Table with p values within the group (amla extract/placebo) and between groups

\begin{tabular}{|c|c|c|c|c|c|c|}
\hline \multicolumn{7}{|l|}{ Triglycerides (mg/dl) } \\
\hline & \multicolumn{2}{|l|}{ Placebo } & \multicolumn{2}{|l|}{ Amla extract } & \multicolumn{2}{|c|}{ Between groups (MW) } \\
\hline & Initial & Final & Initial & Final & Initial & Final \\
\hline Mean TG levels (mg/dl) & 247.617 & 210.469 & 261.106 & 171.939 & & \\
\hline $\mathrm{p}$ (within group) (W) & $p=0.0007$ & & $p<0.0001$ & & $p=0.8367$ & $p=0.0003$ \\
\hline Decrease in TG (n) & 35 & & 44 & & & \\
\hline Increase in TG (n) & 14 & & 4 & & & \\
\hline No change (n) & 0 & & 1 & & & \\
\hline p (chi-square) & $p=0.021$ & & & & & \\
\hline \multicolumn{7}{|l|}{ Total Cholesterol (mg/dl) } \\
\hline & \multicolumn{2}{|l|}{ Placebo } & \multicolumn{2}{|l|}{ Amla extract } & \multicolumn{2}{|c|}{ Between groups (MW) } \\
\hline & Initial & Final & Initial & Final & Initial & Final \\
\hline Mean TC levels (mg/dl) & 225.735 & 212.551 & 231.673 & 177 & & \\
\hline $\mathrm{p}$ (within group) $(\mathrm{W})$ & $p=0.0098$ & & $p<0.0001$ & & $p=0.2707$ & $p=0.0003$ \\
\hline Decrease in TC (n) & 31 & & 40 & & & \\
\hline Increase in TC (n) & 16 & & 9 & & & \\
\hline No change & 2 & & 0 & & & \\
\hline p (chi-square) & $P=0.129$ & & & & & \\
\hline \multicolumn{7}{|c|}{ Low Density Lipoproteins (mg/dl) } \\
\hline & \multicolumn{2}{|l|}{ Placebo } & \multicolumn{2}{|l|}{ Amla extract } & \multicolumn{2}{|c|}{ Between groups (MW) } \\
\hline & Initial & Final & Initial & Final & Initial & Final \\
\hline Mean LDL levels (mg/dl) & 132.155 & 126.059 & 139.963 & 111.531 & & \\
\hline $\mathrm{p}$ (within group) $(\mathrm{W})$ & $p=0.1008$ & & $p<0.0001$ & & $p=0.0404$ & $p=0.0064$ \\
\hline Decrease in LDL (n) & 28 & & 36 & & & \\
\hline Increase in LDL (n) & 20 & & 13 & & & \\
\hline No change (n) & 1 & & 0 & & & \\
\hline p (chi-square) & $P=0.174$ & & & & & \\
\hline \multicolumn{7}{|c|}{ High Density Lipoproteins (mg/dl) } \\
\hline & \multicolumn{2}{|l|}{ Placebo } & \multicolumn{2}{|l|}{ Amla extract } & \multicolumn{2}{|c|}{ Between groups (MW) } \\
\hline & Initial & Final & Initial & Final & Initial & Final \\
\hline Mean HDL levels (mg/dl) & 43.418 & 41.659 & 43.657 & 39.339 & & \\
\hline $\mathrm{p}$ (within group) $(\mathrm{W})$ & $p=0.2849$ & & $p=0.0002$ & & $p=0.5527$ & $p=0.0149$ \\
\hline Decrease in HDL (n) & 28 & & 36 & & & \\
\hline Increase in HDL (n) & 21 & & 12 & & & \\
\hline No change (n) & 0 & & 1 & & & \\
\hline p (chi-square) & $p=0.101$ & & & & & \\
\hline \multicolumn{7}{|c|}{ Atherogenic Index of Plasma } \\
\hline & \multicolumn{2}{|l|}{ Placebo } & \multicolumn{2}{|l|}{ Amla extract } & \multicolumn{2}{|c|}{ Between groups } \\
\hline & Initial & Final & Initial & Final & Initial (MW) & Final (T-test) \\
\hline Mean AIP level & 0.410 & 0.347 & 0.426 & 0.261 & & \\
\hline $\mathrm{p}$ (within group) $(\mathrm{W})$ & $p=0.0098$ & & $p<0.0001$ & & $p=0.8119$ & $p=0.0177$ \\
\hline Decrease in AIP (n) & 31 & & 40 & & & \\
\hline Increase in AIP (n) & 18 & & 8 & & & \\
\hline No change (n) & 0 & & 1 & & & \\
\hline $\mathrm{p}$ (chi-Square) & $p=0.045$ & & & & & \\
\hline
\end{tabular}


Table 2 Table with p values within the group (amla extract/placebo) and between groups (Continued)

\begin{tabular}{|c|c|c|c|c|c|c|}
\hline \multicolumn{7}{|l|}{ CoQ10 (ng/ml) } \\
\hline & \multicolumn{2}{|l|}{ Placebo } & \multicolumn{2}{|c|}{ Amla extract } & \multicolumn{2}{|c|}{ Between groups } \\
\hline & Initial & Final & Initial & Final & Initial (MW) & Final (T-test) \\
\hline Mean CoQ10 levels (ng/ml) & 48.691 & 49.602 & 47.146 & 45.975 & & \\
\hline $\mathrm{p}$ (within group) & \multicolumn{2}{|c|}{$p=0.6744$ (t-test) } & \multicolumn{2}{|c|}{$p=0.2942(W)$} & \multirow[t]{5}{*}{$p=0.7788$} & \multirow[t]{5}{*}{$p=0.4581$} \\
\hline Decrease in CoQ10 (n) & \multicolumn{2}{|l|}{14} & \multicolumn{2}{|l|}{18} & & \\
\hline Increase in CoQ10 (n) & \multicolumn{2}{|l|}{16} & \multicolumn{2}{|l|}{12} & & \\
\hline No change $(n)$ & 0 & & 0 & & & \\
\hline $\mathrm{p}$ (chi-Square) & \multicolumn{2}{|c|}{$p=0.438$} & & & & \\
\hline \multicolumn{7}{|l|}{ Ratio of Apo B/Apo A1 } \\
\hline & \multicolumn{2}{|l|}{ Placebo } & \multicolumn{2}{|c|}{ Amla extract } & \multicolumn{2}{|c|}{ Between groups (MW) } \\
\hline & Initial & Final & Initial & Final & Initial & Final \\
\hline Mean value & 0.869 & 0.853 & 1.004 & 0.948 & & \\
\hline $\mathrm{p}$ (within group) & \multicolumn{2}{|c|}{$p=0.6434$ (t-test) } & \multicolumn{2}{|c|}{$p=0.0419(\mathrm{~W})$} & $p=0.0528$ & $p=0.0866$ \\
\hline Decrease in Apo B/Apo A1 ratio (n) & \multicolumn{2}{|l|}{27} & \multicolumn{2}{|l|}{31} & & \\
\hline Increase in Apo B/Apo A1 ratio (n) & \multicolumn{2}{|l|}{21} & \multicolumn{2}{|l|}{18} & & \\
\hline No change (n) & \multicolumn{2}{|l|}{0} & \multicolumn{2}{|l|}{0} & & \\
\hline p (chi-Square) & \multicolumn{2}{|c|}{$p=0.619$} & & & & \\
\hline
\end{tabular}

$T$-test Independent t-test, $t$-test Paired t test, MW Mann whitney test, $W$ Wilcoxon signed rank test. No change Not included in the calculation

parameter of high predictive value. Forty participants in the study (out of 49) recorded lower AIP values at the end of the study (Table 2).

The second ratio employed in the study is that of apoB and apo A-I. ApoB represents the atherogenic lipoprotein particles and apo A-I represent the anti-atherogenic ones. ApoB is present in VLDL, IDL, small dense LDL with one molecule of apoB in each of these atherogenic particles. Therefore, the total apoB reflects the total number of potentially atherogenic particles. ApoA-I is present in HDL particles and initiates the 'reverse cholesterol transport' by picking up excess cholesterol from peripheral cells and transfer it back to the liver in the HDL particles. In addition, apoA-I manifests anti-inflammatory and antioxidant effects. Thus, apoA-I reflects the athero-protective part of lipoprotein metabolism. The ratio of apoB/apoA-I, thus, reflects the balance of cholesterol transport in a simple way. Thirty one participants (63\%) recorded lower apoB/apo A-I ratios (Table 2.). However, the decrease was not statistically significant.

The robust reduction observed in TG levels points to a potential role for the extract to treat diabetic dyslipidemia in particular wherein the importance shifts from cholesterol to triglycerides. In the Paris Prospective study, hypertriglyceridemia, and not hypercholesterolemia, predicted CVD mortality in a combined group of subjects with impaired glucose tolerance and diabetes [37]. Subjects with impaired glucose tolerance or diabetes at baseline $(n=943)$ were selected from the total population for a separate analysis of coronary heart disease mortality risk factors. After a follow-up of 11 years, in multivariate regression analysis using the Cox model, TG plasma level was the only factor positively and significantly associated with death from CVD ( $\mathrm{p}$ less than 0.006). After a mean follow-up of 15 years, significant multivariate predictors of CVD death were plasma TG level, systolic blood pressure, and smoking. This epidemiological evidence of the consistency of hypertriglyceridemia as the most important predictor of CVD mortality in subjects with impaired glucose tolerance or diabetes suggests a possible role of hypertriglyceridemia in the excessive occurrence of atherosclerotic vascular disease in this category of patients.

Statins are the most employed lipid-lowering drugs used in clinical practice and are widely used to target LDL-C levels in primary and secondary cardiovascular prevention. Statins are generally very well tolerated but can cause swelling and tenderness in the muscles and in a very few cases lead to muscle damage. Independent of their hypolipidemic properties, statins interfere with events involved in bone formation and impede tumor cell growth. Other side effects include liver damage, increase in blood sugar and memory loss [38]. One of the serious drawbacks of statin therapy is the decrease in CoQ10 levels. In common with cholesterol, CoQ10 also uses mevalonate as its biosynthetic precursor. CoQ10 is an important factor in mitochondrial respiration. Primary and secondary deficiencies of CoQ10 result in a number of neurologic and myopathic syndromes. The 
association between treatment with statins and new-onset diabetes is of concern. Such an association has also been confirmed by some cohort studies and meta-analyses [39-42].

In February 2012, the Food and Drug Administration changed the safety label of statins to indicate the risk of increased HbA1c and fasting serum glucose levels [43]. Statins do not treat hypertriglyceridemia. Amla treatment caused only minor variations in CoQ10 levels (Table 2). This may indicate that amla inhibits some stage of cholesterol synthesis other than HMG CoA reductase. A second possibility is that the extract may facilitate increased LDL receptor expression.

Amla has been studied before [22-30] to treat dyslipidemia. But, the extract used in this study is qualitatively different from the earlier extracts wherein only the fleshy part of the amla fruits was used. The whole fruit (including a hard seed) has been used in preparing the extract used in the present study. Ninety eight participants were enrolled in the study and all completed the study. Treatment compliance for this study was extremely high with the Mean Value $(\mathrm{MV}=87.5 \%)$ between both study arms $(87.7 \%$ for amla extract and $87.3 \%$ for placebo). The very close mean values (MV), thus supporting the conclusion that compliance in both groups was similar. Furthermore, the lack of clinically significant abnormalities in physical findings in both groups, as observed on the screening and study visits as well as no withdrawals or drop outs, further supports the conclusion of good compliance by all 98 subjects. The four adverse events reported in the study were mild in nature and resolved with routine medications.

\section{Conclusions}

A very significant reduction in the TC, TG, AIP and other lipid parameters strongly supports the efficacy of amla extract in patients at risk for CVD. Of note, the observed effects were noticed during a short span of only 12 weeks indicating its utility in the management of multiple components of dyslipidemia and cardiovascular health. An additional benefit of the use of amla extract over other standard of care therapies is the lack of change in serum CoQ10 levels. This suggests that amla extract may be a safer alternative to statins without severe adverse effects. A larger and longer term study is warranted to elucidate the mechanism of action of amla extract in dyslipidemic patients.

\section{Additional files}

Additional file 1: Characterization of amla extract. (DOC $33 \mathrm{~kb}$ )

Additional file 2: Details of study sites. (DOCX $11 \mathrm{~kb}$ )

Additional file 3: Clinical study protocol. (PDF $343 \mathrm{~kb}$ )
Additional file 4: CONSORT Checklist. (DOC $219 \mathrm{~kb}$ )

Additional file 5: Full data of all visits. (DOCX $25 \mathrm{~kb}$ )

Additional file 6: Safety parameters. (DOCX 28 kb)

\section{Abbreviations}

AIP: Atherogenic index of the plasma; Apo A1: Apolipoprotein A1; Apo B: Apolipoprotein B; CoQ10: Coenzyme Q10; CVD: Cardiovascular disease: HDL: High density lipoproteins; IDL: Intermediate density lipoproteins; LDL: Low density lipoproteins; T2DM: Type 2 diabetes mellitus; TC: Total cholesterol; TG: triglyceride; TSH: Thyroid stimulating hormone; VLDL: Very low density lipoproteins

\section{Acknowledgements}

The authors acknowledge the gracious help of Arjuna Natural Ltd., Kerala for providing amla extract (Trilow) and placebo capsules to conduct the study.

\section{Funding}

The study was sponsored by Arjuna Natural Ltd., Kerala. The funders had no role in study design, data collection and analysis, decision to publish, or preparation of the manuscript.

Availability of data and materials

The datasets used and/or analysed during the current study are available from the corresponding author on reasonable request.

\section{Authors' contributions}

$H U, P S, A P, D S, S G$ and AG were involved in study concept and design, acquisition of data, analysis and interpretation of data, drafting of the manuscript. All authors have read and approved the final manuscript.

\section{Ethics approval and consent to participate}

The study protocol was approved by respective institutional ethics committees where study was conducted, i.e. Mysore Clinical Research Ethics Committee on 22/2/2015 (study site: Aadhitya Adhikari Hospital, Contour Road, Gokulam, Mysore-570,002), Life Care Hospital Institutional Ethics Commitee on 15/3/2015 (study site: LifeCare Hospital, 99, OM Complex, 20th Main, Gangothri Circle, BTM 1st Stage, Bangalore-560,029), Sri Venkateshwara Hospital Ethics Committee on 15/3/2015 (Study site: Sri Venkateshwara Hospital, No.86, Hosur Main Road, Madiwala, Bangalore- 560,068) and Prashanth Hospital Ethics Committee on 17/3/2015 (study site: Prashanth Hospital, Bommanahalli Circle, Hosur Main Road, Bangalore-560,068) and registered with Clinical Trials Registry- India at www.ctri.nic.in (Registration number: CTRI/2015/04/005682) on 8 April 2015 (retrospectively registered). Any study related activity was undertaken only after subjects voluntarily signed the consent form to participate in the study.

\section{Consent for publication}

Not applicable.

\section{Competing interests}

The authors declare that they have no competing interests.

\section{Publisher's Note}

Springer Nature remains neutral with regard to jurisdictional claims in published maps and institutional affiliations.

\section{Author details}

${ }^{1}$ Aadhitya Adhikari Hospital, Contour Road, Gokulam, Mysore 570002, India. ${ }^{2}$ LifeCare Hospital, No.99, OM Complex, 20th Main, Gangothri Circle, BTM 1st Stage, Bangalore 560029, India. ${ }^{3}$ Sri Venkateshwara Hospital, No.86, Hosur Main Road, Madiwala, Bangalore 560068, India. ${ }^{4}$ Syncretic Clinical Research Services, No. 4, 5th cross, 11 th Main Road, Vasanthnagar, Bangalore 560052, India. ${ }^{5}$ Amrita School of Pharmacy, Amrita Institute of Medical Sciences and Research Centre, Amrita Vishwa Vidyapeetham, Kochi 682041, India. ${ }^{6}$ Center for Gastrointestinal Research, Center for Translational Genomics and Oncology, Baylor Scott \& White Research Institute and Sammons Cancer Center, Baylor University Medical Center, Dallas, Texas, 3410 Worth Street, Suite 610, Dallas, TX 75246, USA. 
Received: 26 April 2018 Accepted: 8 January 2019

\section{Published online: 22 January 2019}

\section{References}

1. Assmann G, Schulte $H$. Relation of high-density lipoprotein cholesterol and triglycerides to incidence of atherosclerotic coronary artery disease (the PROCAM experience). Prospective Cardiovascular Munster study Am J Cardiol. 1992;70(7):733-7 PubMed PMID: 1519522.

2. Davis NE. Atherosclerosis--an inflammatory process. J Insur Med. 2005;37(1): 72-5 PubMed PMID: 15895704.

3. Dobiásová $M$, Frohlich J. The plasma parameter log (TG/HDL-C) as an atherogenic index: correlation with lipoprotein particle size and esterification rate in apoB-lipoprotein-depleted plasma (FER(HDL)). Clin Biochem. 2001;34(7):583-8 PubMed PMID: 11738396.

4. Zhu XW, Deng FY, Lei SF. Meta-analysis of Atherogenic index of plasma and other lipid parameters in relation to risk of type 2 diabetes mellitus. Prim Care Diabetes. 2015;9(1):60-7. https://doi.org/10.1016/j.pcd.2014.03.007 PubMed PMID: 24810146.

5. Beisiegel U. Lipoprotein metabolism. Eur Heart J. 1998;19(Suppl A):A20-3 PubMed PMID: 9519338.

6. Frank PG, Marcel YL. Apolipoprotein A-l: structure-function relationships. J Lipid Res. 2000;41(6):853-72 PubMed PMID: 10828078.

7. Packard CJ, Shepherd J. Lipoprotein heterogeneity and apolipoprotein B metabolism. Arterioscler Thromb Vasc Biol. 1997;17(12):3542-56 PubMed PMID: 9437204.

8. Rifai N, Chapman JF, Silverman LM, Gwynnes JT. Review of serum lipids and apolipoproteins in risk-assessment of coronary heart disease. Ann Clin Lab Sci. 1988;18(6):429-39 PubMed PMID: 3071240.

9. Zambon A, Brown BG, Deeb SS, Brunzell JD. Genetics of apolipoprotein B and apolipoprotein Al and premature coronary artery disease. J Intern Med. 2006;259(5):473-80. https://doi.org/10.1111/j.1365-2796.2006.01645.x PubMed PMID: 16629853.

10. Walldius G, Jungner I, Holme I, Aastveit AH, Kolar W, Steiner E. High apolipoprotein B, low apolipoprotein A-l, and improvement in the prediction of fatal myocardial infarction (AMORIS study): a prospective study. Lancet. 2001;358(9298):2026-33. https://doi.org/10.1016/S01406736(01)07098-2 PubMed PMID: 11755609

11. Yusuf S, Hawken S, Ounpuu S, Dans T, Avezum A, Lanas F, et al. Effect of potentially modifiable risk factors associated with myocardial infarction in 52 countries (the INTERHEART study): case-control study. Lancet. 2004 364(9438):937-52. https://doi.org/10.1016/S0140-6736(04)17018-9 PubMed PMID: 15364185

12. Vaessen SF, Schaap FG, Kuivenhoven JA, Groen AK, Hutten BA, Boekholdt $\mathrm{SM}$, et al. Apolipoprotein A-V, triglycerides and risk of coronary artery disease: the prospective Epic-Norfolk population study. J Lipid Res. 2006; 47(9):2064-70. https://doi.org/10.1194/jlr.M600233-JLR200 PubMed PMID: 16769999.

13. Dunder $\mathrm{K}$, Lind L, Zethelius B, Berglund L, Lithell $H$. Evaluation of a scoring scheme, including proinsulin and the apolipoprotein B/apolipoprotein A1 ratio, for the risk of acute coronary events in middle-aged men: Uppsala longitudinal study of adult men (ULSAM). Am Heart J. 2004;148(4):596-601. https://doi.org/10.1016/j.ahj.2004.03.021 PubMed PMID: 15459588.

14. Meisinger $C$, Loewel H, Mraz W, Koenig W. Prognostic value of apolipoprotein $B$ and $A-I$ in the prediction of myocardial infarction in middle-aged men and women: results from the MONICA/KORA Augsburg cohort study. Eur Heart J. 2005;26(3):271-8. https://doi.org/10.1093/ eurheartj/ehi003 PubMed PMID: 15618061

15. Sierra-Johnson J, Romero-Corral A, Somers VK, Lopez-Jimenez F, Walldius G, Hamsten A, et al. ApoB/apoA-I ratio: an independent predictor of insulin resistance in US non-diabetic subjects. Eur Heart J. 2007;28(21):2637-43. https://doi.org/10.1093/eurheartj/ehm360 PubMed PMID: 17766927.

16. Thompson A, Danesh J. Associations between apolipoprotein B, apolipoprotein $\mathrm{Al}$, the apolipoprotein $\mathrm{B} / \mathrm{Al}$ ratio and coronary heart disease: a literature-based meta-analysis of prospective studies. J Intern Med. 2006; 259(5):481-92. https://doi.org/10.1111/j.1365-2796.2006.01644.x PubMed PMID: 16629854

17. Sniderman AD, Jungner I, Holme I, Aastveit A, Walldius G. Errors that result from using the TC/HDL C ratio rather than the apoB/apoA-I ratio to identify the lipoprotein-related risk of vascular disease. J Intern Med. 2006;259(5): 455-61. https://doi.org/10.1111/j.1365-2796.2006.01649.x PubMed PMID: 16629851.
18. Ginsburg GS, Safran C, Pasternak RC. Frequency of low serum high-density lipoprotein cholesterol levels in hospitalized patients with "desirable" total cholesterol levels. Am J Cardiol. 1991;68(2):187-92 PubMed PMID: 2063780.

19. van Lennep JE, Westerveld HT, van Lennep HW, Zwinderman AH, Erkelens DW, van der Wall EE. Apolipoprotein concentrations during treatment and recurrent coronary artery disease events. Arterioscler Thromb Vasc Biol. 2000;20(11):2408-13 PubMed PMID: 11073845.

20. Sniderman AD, Pedersen T, Kjekshus J. Putting low-density lipoproteins at center stage in atherogenesis. Am J Cardiol. 1997;79(1):64-7 PubMed PMID: 9024738.

21. Carnevale Schianca GP, Pedrazzoli R, Onolfo S, Colli E, Cornetti E, Bergamasco L, et al. ApoB/apoA-I ratio is better than LDL-C in detecting cardiovascular risk. Nutr Metab Cardiovasc Dis. 2011;21(6):406-11. https:// doi.org/10.1016/j.numecd.2009.11.002 PubMed PMID: 20171854.

22. Mathur R, Sharma A, Dixit VP, Varma M. Hypolipidaemic effect of fruit juice of Emblica officinalis in cholesterol-fed rabbits. J Ethnopharmacol. 1996; 50(2):61-8 PubMed PMID: 8866725.

23. Jacob A, Pandey M, Kapoor S, Saroja R. Effect of the Indian gooseberry (amla) on serum cholesterol levels in men aged 35-55 years. Eur J Clin Nutr. 1988;42(11):939-44 PubMed PMID: 3250870.

24. Anila L, Vijayalakshmi NR. Flavonoids from Emblica officinalis and Mangifera indica-effectiveness for dyslipidemia. J Ethnopharmacol. 2002;79(1):81-7 PubMed PMID: 11744299.

25. Antony B, Merina B, Sheeba V, Mukkadan J. Effect of standardized Amla extract on atherosclerosis and dyslipidemia. Indian J Pharm Sci. 2006;68: 437-41.

26. Mishra M, Pathak UN, Khan AB. Emblica officinalis Gaertn and serum cholesterol level in experimental rabbits. Br J Exp Pathol. 1981;62:526-8.

27. Thakur CP, Mandal K. Effect of Emblica officinalis on cholesterol-induced atherosclerosis in rabbits. Ind J Med Res. 1984;79:142-6.

28. Antony B, Benny M, Kaimal TN. A pilot clinical study to evaluate the effect of Emblica officinalis extract (Amlamax) on markers of systemic inflammation and dyslipidemia. Indian J Clin Biochem. 2008;23(4):378-81. https://doi.org/10.1007/s12291-008-0083-6 PubMed PMID: 23105791; PubMed Central PMCID: PMCPMC3453138.

29. Antony B, Merina B, Sheeba V. Amlamax in the management of dyslipidemia in humans. Indian J Pharm Sci. 2008;70(4):504-7. https://doi. org/10.4103/0250-474X.44604 PubMed PMID: 20046781; PubMed Central PMCID: PMCPMC2792547.

30. Gopa B, Bhatt J, Hemavathi KG. A comparative clinical study of hypolipidemic efficacy of Amla (Emblica officinalis) with 3-hydroxy-3methylglutaryl-coenzyme-a reductase inhibitor simvastatin. Indian J Pharmacol. 2012;44(2):238-42. https://doi.org/10.4103/0253-7613.93857 PubMed PMID: 22529483; PubMed Central PMCID: PMCPMC3326920.

31. Muthayya S, Sugimoto JD, Montgomery S, Maberly GF. An overview of global rice production, supply, trade, and consumption. Ann N Y Acad Sci. 2014;1324:7-14 PubMed PMID: 25224455.

32. Ray M, Ghosh K, Singh S, Mondal KC. Folk to functional: an explorative overview of rice-based fermented foods and beverages in India. J Ethnic Foods. 2016;3(1):5-18.

33. Cicero AFG, Derosa G. Rice bran and its main components: potential role in the management of coronary risk factors. Curr Top Nutraceutical Res. 2005;3:29-46.

34. Borresen EC, Jenkins-Puccetti N, Schmitz K, Brown DG, Pollack A, Fairbanks A. A pilot randomized controlled clinical trial to assess tolerance and efficacy of navy bean and Rice bran supplementation for lowering cholesterol in children. Glob Pediatr Health. 2017;16, 4. https://doi.org/10. 1177/2333794X17694231 PubMed PMID: 28345013.

35. Dobiasova M. Atherogenic index of plasma [log(triglycerides/HDL-cholesterol)]: theoretical and practical implications. Clin Chem. 2004;50(7):1113-5. https://doi. org/10.1373/clinchem.2004.033175 PubMed PMID: 15229146.

36. Havel RJ. Remnant lipoproteins as therapeutic targets. Curr Opin Lipidol 2000;11(6):615-20 PubMed PMID: 11086335.

37. Fontbonne A, Eschwège E. Insulin-resistance, hypertriglyceridaemia and cardiovascular risk: the Paris prospective study. Diabete Metab. 1991;17(1 Pt 2):93-5 PubMed PMID: 1936489.

38. Joseph JP, Afonso M, Berdai D, Salles N, Benard A, Gay B, et al. Benefits and risks for primary prevention with statins in the elderly. Presse Med. 2015; 44(12 Pt 1):1219-25. https://doi.org/10.1016/j.lpm.2015.09.015 PubMed PMID: 26585744

39. Ridker PM, Danielson E, Fonseca FA, Genest J, Gotto AM Jr, Kastelein JJ, et al. Rosuvastatin to prevent vascular events in men and women with 
elevated C-reactive protein. N Engl J Med. 2008;359(21):2195-207. https:// doi.org/10.1056/NEJMoa0807646 PubMed PMID: 18997196.

40. Sattar N, Preiss D, Murray HM, Welsh P, Buckley BM, de Craen AJ, et al. Statins and risk of incident diabetes: a collaborative meta-analysis of randomised statin trials. Lancet. 2010;375(9716):735-42. https://doi.org/10. 1016/S0140-6736(09)61965-6 PubMed PMID: 20167359.

41. Wang KL, Liu CJ, Chao TF, Huang CM, Wu CH, Chen SJ, et al. Statins, risk of diabetes, and implications on outcomes in the general population. J Am Coll Cardiol. 2012;60(14):1231-8. https://doi.org/10.1016/j.jacc.2012.05.019 PubMed PMID: 22884288.

42. Waters DD, Ho JE, DeMicco DA, Breazna A, Arsenault BJ, Wun CC, et al. Predictors of new-onset diabetes in patients treated with atorvastatin: results from 3 large randomized clinical trials. J Am Coll Cardiol. 2011;57(14): 1535-45. https://doi.org/10.1016/j.jacc.2010.10.047 PubMed PMID: 21453832.

43. US Food and Drug Administration. FDA drug safety communication: important safety label changes to cholesterol lowering statin drugs. www. fda.gov/Drugs/DrugSafety/ucm293101.htm

Ready to submit your research? Choose BMC and benefit from:

- fast, convenient online submission

- thorough peer review by experienced researchers in your field

- rapid publication on acceptance

- support for research data, including large and complex data types

- gold Open Access which fosters wider collaboration and increased citations

- maximum visibility for your research: over $100 \mathrm{M}$ website views per year

At $\mathrm{BMC}$, research is always in progress.

Learn more biomedcentral.com/submissions 